\title{
PROBLEMATIZANDO PRÁTICAS ESCOLARES NA EDUCAÇÃO INFANTIL
}

\section{PROBLEMATIZIG SCHOOL PRACTICE IN CHIL- DHOOD EDUCATION}

\section{Rodrigo Saballa de CARVALHO*}

Resumo: O presente artigo aborda parte dos resultados obtidos em uma pesquisa de Mestrado que teve como propósito problematizar as práticas escolares e o disciplinamento dos corpos no contexto de uma Escola Municipal de Educação Infantil. Tal empreendimento possibilitou a tematização das práticas escolares enquanto instâncias disciplinares, exercitando a compreensão das relações de poder, dos movimentos de resistência e da pluralidade dos sujeitos que compõem o espaço escolar. A prática escolar da seleção de alunos, composta por entrevistas e testes de desenho, é entendida como uma prática de exame cujo intuito principal é o de conhecer a criança no detalhe para, assim, melhor governá-la. As práticas escolares do cotidiano são consideradas, na pesquisa, como os momentos de alimentação, de descanso e de brincadeira "livre". A prática escolar dos rituais comemorativos é vista como o conjunto de festas que fazem parte do calendário escolar e são realizadas na instituição. Sendo assim, ao apresentar e discutir tais práticas escolares no decorrer do artigo, não se estão apontando alternativas de mudança para as propostas que vêm sendo desenvolvidas na Escola de Educação Infantil, mas considerações que possibilitem refletir, discutir e "desestabilizar" o que tem sido considerado, muitas vezes, de forma "natural" e indelével ao âmbito institucional. Dessa forma, talvez seja possível compreender as lógicas que disciplinam e

* Mestre em Educação pela Universidade Federal do Rio Grande do Sul (UFRGS) e Doutorando em Educação pela mesma instituição. E-mail: rsaballa@terra.com.br 
constituem professores, alunos, pais, enquanto sujeitos em redes de relações de poder.

Palavras-chave: Educação Infantil. Práticas escolares. Disciplinamento.

Abstract: The present article presents part of the results obtained from a Master's degree research that aimed at problematizing school practices and the establishment of school behavior in a Municipal Childhood Education School. The research allowed the study of school practices as behavior settings, the comprehension of the power relations, the resistance movements and of the numerous subjects that make up the school space. The school practice of selecting students by means of interviews and drawing tests is understood as an assessment practice with the main goal of knowing children well so that they can be best oriented. The day-to-day school practices observed were the eating moments, the resting moments and the moments of "free" play. The school practice of commemorative rituals is seen as the set of parties that form the school calendar and are celebrated in the schools. Therefore, when the school practices are presented and discussed in this article, it is not the intention to suggest alternatives for the proposals that have been developed in Childhood Education Schools, but should be seen as forms that allow the reflection, discussion and "unbalance" of what has been considered many times as "natural" and indelible in the school context. This way, it might be possible to understand the logical thinking that guide and are part of teachers, students and parents as the subjects in the networks of power relations.

Keywords: Childhood education. School practice. Establishment of school behavior. 


\section{INTRODUÇÃO}

O presente artigo aborda parte dos resultados obtidos em uma pesquisa de Mestrado, de inspiração etnográfica, que teve como propósito discutir e problematizar as práticas escolares e o disciplinamento dos corpos no contexto de uma Escola Municipal de Educação Infantil, localizada na Região Metropolitana de Porto Alegre/ RS. Nessa perspectiva, tal empreendimento considerou os indivíduos escolares (crianças e adultos) como sujeitos engendrados pela ação do poder disciplinar e possibilitou a tematização das práticas escolares e de sua produtividade enquanto instâncias disciplinares, exercitando (na medida do possível) a compreensão das relações de poder, dos movimentos de resistência e da pluralidade daqueles que compõem o espaço escolar.

A partir dessa discussão, através das práticas escolares desenvolvidas na instituição de Educação Infantil, foram analisados os aspectos disciplinares (controle dos tempos/espaços e corpos) a partir da ênfase pedagógica de que (muitas vezes) o disciplinamento visa, principalmente, à normalização de certos comportamentos estabelecidos como incondicionalmente necessários. Desse modo, ao realizar tal problematização, evidencia-se que embora as crianças sejam o principal alvo do disciplinamento, professoras, educadoras, funcionárias, equipe diretiva e famílias, de alguma forma, também disciplinam e são disciplinados, já que são "personagens" integrantes do jogo de correlação de forças que se apresenta no "cenário" escolar. Pode-se dizer, portanto, que tal jogo operacionaliza-se (entre outros modos) através das diferentes práticas escolares desenvolvidas na instituição.

Assim, a partir da apresentação da pesquisa, é relevante contextualizar o campo de estudos que possibilitou o seu desenvolvimento. Nela destacam-se os Estudos Culturais e os estudos desenvolvidos por Michel Foucault. Tais ferramentas teóricas são apresentadas com a intenção de ressaltar a importante tentativa de encontrar pontos de conexão entre esses dois "campos". A partir das contribuições dos autores Cary, Treichler e Grossberg (2002), é possível dizer que os Estudos Culturais podem ser considerados ativa e agressivamente antidisciplinares, podendo ser vistos como um empreendimento diversificado e controverso. Tais características, de certa forma, asseguram uma relação permanentemente "desconfortável" com as 
disciplinas acadêmicas, à medida que os Estudos Culturais se utilizam de campos diversos para produzir o conhecimento exigido por projetos particulares. Trabalhar nessa perspectiva analítica possibilita exercitar a compreensão das relações de poder e os modos como nos constituímos enquanto sujeitos dentro delas. Nesse sentido, Costa, Silveira e Sommer (2003, p.40) ressaltam que as pesquisas desenvolvidas pelos Estudos Culturais "utilizam-se da etnografia, da análise textual e do discurso, da Psicanálise e de tantos outros caminhos investigativos que são inventados para poder compor seus objetos de estudo e corresponder a seus propósitos".

Justamente a partir dessas considerações, é possível estabelecer uma aproximação dos Estudos Culturais e do pensamento de Michel Foucault. De acordo com Veiga-Neto (2000, p.40), tal campo, "ao salientar o papel do poder - ao colocar o poder no centro das significações e identidades culturais -, abre uma frente para que se possa construir uma ponte com o pensamento" do referido filósofo. Dessa forma, é preciso levar em consideração que, no referencial foucaultiano, o poder é produtivo, pois produz sujeitos, conhecimentos e comportamentos, entre outras manifestações, através da invenção de estratégias que o potencializam e do engendramento de saberes que o justificam de forma econômica. Sendo assim, na próxima seção serão discutidos os conceitos que possibilitaram as operações analíticas e os processos metodológicos da pesquisa.

\section{DELINEANDO OS CONCEITOS E OS PROCESSOS METO- DOLÓGICOS}

Tendo situado o campo de estudos, é relevante destacar os conceitos de poder disciplinar, práticas e corpo, pois os mesmos foram considerados como sendo centrais para o desenvolvimento das análises realizadas a partir dos dados produzidos na pesquisa.

O poder disciplinar é, geralmente, referido por Foucault (1987), através do termo disciplinas. Nesse sentido, é possível dizer que as disciplinas produzem indivíduos e estabelecem posições a eles, através das formas como os vinculam e os fixam no espaço, de como organizam as atividades, de como imprimem o tempo no corpo humano e de como combinam a utilização de suas forças. A partir do uso de tal termo, o referido filósofo pretendeu enfatizar as várias técnicas que passaram a ser utilizadas de forma sistematizada nas diferentes 
instituições sociais através de operações que tiveram (e têm) como intuito o direcionamento da vida e do corpo dos indivíduos, ou seja, a ordenação das multiplicidades humanas. A invenção técnica dessa nova maneira de "administrar" os homens, controlar suas multiplicidades, ocorreu devido às mudanças no sistema do poder disciplinar. Nas sociedades ocidentais, com o crescente processo de urbanização e industrialização, desenvolveu-se uma série de técnicas encarregadas de vigiar e controlar o comportamento dos indivíduos, tendo em vista a utilização deles no aparelho de produção. Dessa forma, iniciou-se o processo de investimento nos corpos dos indivíduos, situando-os onde fossem mais úteis e formando-os para que desenvolvessem as habilidades pretendidas. Nesse sentido, é importante destacar o dito por Foucault (1987, p.127), quando afirma que:

O momento histórico das disciplinas é o momento em que nasce uma arte do corpo humano, que visa não unicamente ao aumento de suas habilidades, nem tampouco aprofundar sua sujeição, mas à formação de uma relação que, no mesmo mecanismo, o torna tanto mais obediente quanto é mais útil, e inversamente. Forma-se, então, uma política das coerções, que são um trabalho sobre o corpo, uma manipulação calculada de seus elementos, de seus gestos, de seus comportamentos. O corpo humano entra numa maquinaria de poder que o esquadrinha, o desarticula e o recompõe.

A partir das considerações do autor, é possível dizer que o funcionamento de tal sistema tornou-se possível através da produção de saberes e da organização de inúmeras práticas que passaram a disciplinar os indivíduos, submetendo-os a um relacionamento consigo mesmos e com os outros a partir desses conhecimentos produzidos e reconhecidos como verdadeiros. Desse modo, é importante esclarecer que as práticas, conforme Foucault (2003b, p. 338), "são consideradas como lugar do que se diz e do que se faz das regras que se impõem e das razões que se dão, dos projetos e das evidências". As práticas têm, ao mesmo tempo, efeitos de prescrição (em relação ao que se deve fazer) e efeitos de codificação (em relação ao que se deve saber). $O$ produtivo investimento das disciplinas sobre o corpo, operacionalizadas através de técnicas específicas de ação sobre o mesmo, possibilita depreender que tais relações de poder o dirigem, moldam, treinam, manipulam, aperfeiçoam e educam, marcando-o através de sinais, 
obrigações, limitações e possibilidades de resistência. À medida que o poder age diretamente sobre o corpo, ele o torna alvo e instrumento de sua ação, utilizando-se de uma variedade de formas.

Nesse sentido, na perspectiva foucaultiana o corpo é entendido como superfície de inscrição dos acontecimentos (inteiramente marcado de história), pois é considerado como uma construção sobre a qual são conferidas diferentes marcas, em diferentes tempos, espaços, grupos sociais, entre outros exemplos possíveis. De acordo com Goellner (2003, p.28), “o corpo não é algo dado a priori, nem mesmo universal: o corpo é provisório, mutável e mutante, suscetível a inúmeras intervenções". O corpo é considerado um sistema vivo (inter-relacionado com o meio), constituído por múltiplos processos que são corporificados pelos indivíduos, sendo significado na cultura e continuamente por ela alterado.

A partir de tais conceitos, foram discutidas as seguintes questões no decorrer da pesquisa: Como se exerce o poder disciplinar nas práticas escolares que são desenvolvidas na instituição de Educação Infantil pesquisada? Quais os efeitos de tais práticas no diz respeito ao disciplinamento dos corpos?

Nessa perspectiva, é importante salientar que as práticas escolares inserem-se nos modos de objetivação e subjetivação, por isso não são tomadas como algo repressivo, cujo resultado seria o constrangimento dos indivíduos. Conforme Veiga-Neto (2000, p.52), as "práticas são vistas como produtivas, pois se instauram para nos tornarem sujeitos modernos, cidadãos de uma sociedade disciplinar e, por isso mesmo, capazes de autogoverno". Assim, o poder é entendido através da noção de rede que supõe um fluxo contínuo proveniente de diferentes articulações sociais instáveis. Desse modo, é importante ressaltar que, através das questões apresentadas, foram discutidas, problematizadas e desestabilizadas práticas escolares que, muitas vezes, são consideradas naturais no âmbito institucional, já que o poder disciplinar - por ser operatório, por ser relação de forças - sempre é suscetível a divergências, resistências e (re)siginificações por parte dos indivíduos. Ressalta-se, portanto, que as práticas escolares analisadas foram colocadas sob suspeição, evidenciando-se a sua "fabricação" a partir da rede de relações de poder que se estabelecem no interior das configurações institucionais, assim como sua produtividade em termos de efeitos.

A partir da apresentação das questões que nortearam a pesqui- 
sa, é interessante apresentar (ainda que de forma sucinta) os processos metodológicos que constituíram o percurso investigativo. No período de julho a dezembro de 2003, foram observadas práticas escolares desenvolvidas em uma Escola Municipal de Educação Infantil, através do acompanhamento das propostas vivenciadas pelas crianças da turma do Pré A - formada por dezessete crianças na faixa etária dos cinco anos de idade, as quais permaneciam em turno integral na instituição - , pelas professoras, educadoras, funcionárias, equipe diretiva, assessoria pedagógica e famílias.

Tal processo de "produção de dados" teve "inspiração etnográfica", sendo realizado através de observações, registros em diário de campo, entrevistas (semi-estruturadas), conversas informais, elaboração de fichários, análise de documentos, registros fotográficos e gravações. Desse modo, através dos "dados" produzidos durante a pesquisa de campo, da leitura do referencial foucaultiano, foram destacadas enquanto corpus de análise as práticas escolares mais recorrentes no decorrer do trabalho, tais como: a seleção de alunos/ as e a organização das turmas, as práticas do cotidiano (alimentação, descanso e brincadeira "livre") e os rituais comemorativos (festas escolares). Sendo assim, na próxima seção será apresentada e discutida a prática escolar da seleção de alunos/as e a organização das turmas.

\section{A SELEÇÃo DE ALUNOS/AS E A AORGANIZAÇÃO DAS TURMAS}

A partir da análise dos documentos (ficha de entrevista com a família, ficha de entrevista com a criança candidata e registros sobre o teste do desenho da figura humana/casa realizados com a mesma) que compõem o processo de seleção das crianças realizado na Escola de Educação Infantil pesquisada, assim como o processo de organização das turmas, a partir das "características" comportamentais das crianças, foi possível destacar que tal prática é constituída a partir de vários campos discursivos (pedagógico, médico, psicológico, psicopedagógico e de assistência social). Esses campos assinalam diferentes posições para as crianças, famílias, docentes e lutam pela imposição de significados acerca do que é ser aluno/a de determinada turma, professora, educadora e familiar. Desse modo, enquanto tecnologia disciplinar implicada na normalização dos indivíduos, a referida 
prática os registra, distribui, classifica, categoriza e introduz em um sistema de objetivação que localiza, singulariza e visualiza cada um em suas características. Tal argumentação pode ser evidenciada em uma das fichas analisadas, a partir das constatações realizadas pela entrevistadora (docente), após a entrevista individual com um candidato a vaga na escola:

O candidato não demonstra autonomia e é inseguro. Preocupou-se em responder a todas as questões, mas parece viver em extrema carência. No final da entrevista, ele chorou solicitando a mãe. Conversei com ela e orientei que a mesma desenvolva mais autonomia em seu filho, pois, dessa forma, ele terá dificuldades no processo de adaptação. Solicitei à mãe os exames que comprovam que o menino é HIV positivo, pois ela havia salientado essa situação desde o nosso primeiro encontro.

As caracterizações atribuídas ao menino, como: "não demonstra autonomia, é inseguro, parece viver em extrema carência, terá dificuldades no processo de adaptação", são decorrentes da observação realizada pela docente. Portanto, pode-se dizer que, através do "percebido e do falado", o candidato é posto em um campo de vigilância e situado (igualmente) em uma rede de anotações escritas. Nessa perspectiva, conforme Corazza (2001, p.45), "tem-se uma forma mista do percebido e do falado, da questão e da observação, da pergunta e do visto". As referidas considerações demonstram que os procedimentos de entrevista, por serem acompanhados de um sistema de observação, questionamento e registro, constituem um "poder de escrita" que é considerado um elemento importante nas engrenagens da disciplina.

Prosseguindo a análise, é interessante retomar os "modos de ver e narrar" o menino, apresentados nas "constatações" da entrevistadora quando afirma que o "candidato não demonstra autonomia e é inseguro". Conforme Houaiss (2004, p.351), autonomia pode ser considerada a "capacidade de se autogovernar; direito de se administrar livremente; direito de um indivíduo tomar decisões livremente", entre outras acepções da palavra. Por outro lado, é preciso levar em consideração que na análise que vem sendo desenvolvida, conforme Silva (1999), autonomia significa também mais governo (no sentido de controle de conduta). Sendo assim, ao ser descrito, o menino torna-se 
objeto de estudo e análise, pois é "capturado" pela escola, que tem como um de seus propósitos a "formação" do aluno, para que ele possa tornar-se um indivíduo autogovernado no futuro.

Tal propósito é partilhado com a mãe do menino, quando orientada pela docente a "desenvolver" autonomia em seu filho para que ele não enfrente problemas no processo de adaptação escolar. Nesse sentido, é possível destacar que esse processo de adaptação pode ser considerado uma estratégia (disciplinar) de "preparação" da criança que emigra da família para o novo espaço, que é a escola. Assim, a escola muitas vezes "orienta" as famílias e as crianças em relação às suas regras e funcionamento. Essas orientações que fazem parte da organização institucional podem ser consideradas implicadas em relações de poder, que são tanto menos visíveis quanto mais físicas e materialmente estão presentes. Nesse sentido, é relevante apresentar as constatações da entrevistadora em relação ao desenho da figura humana realizado pelo candidato referido anteriormente, pois tais ditos corroboram os argumentos apresentados até o momento:

O desenho da figura humana do candidato é muito primário para idade de 5 anos. Tal desenho demonstra que o menino não teve muitas experiências com o material proposto. O corpo desenhado apresenta somente a cabeça e duas pernas de onde saem os braços. O rosto não apresenta os detalhes como olhos, orelhas, boca, etc. Ao lado da figura humana, o menino desenhou um leão. $O$ desenho do leão extrapolou a proposta. Percebi que ele também não sabe escrever o seu nome, pois escreveu apenas duas letras. É importante dizer que o desenho não apresenta base. O aluno é imaturo para sua idade e pode apresentar problemas futuros de relacionamento.

Com esse excerto é importante salientar que os registros de observação e as constatações apresentadas na ficha demonstram, entre outros aspectos, uma "vontade de verdade" que se operacionaliza através da descrição (minuciosa) do comportamento da criança durante a realização do desenho, classificando, selecionando, controlando e posicionando o candidato.

É a partir das considerações apresentadas que penso ser possível realizar uma aproximação com as análises desenvolvidas por Walkerdine (1999), em relação à análise de uma ficha de observação e registro utilizada por uma professora de educação infantil durante a 
realização de um jogo com as crianças de sua turma. A autora destaca, em suas análises, que tal prática estabelece, ao mesmo tempo, o que é a criança enquanto objeto visível, quais são os aspectos vistos e classificados, assim como a posição ocupada pela professora enquanto observadora. À medida que são analisados e discutidos os registros da ficha de observação, é possível perceber que esses "modos de ver e de dizer" são, de certa forma, "inseparáveis" de toda uma teoria do "desenvolvimento" infantil e do que torna visível do comportamento da criança. A partir das contribuições da referida autora, é preciso levar em consideração que os registros de observação também podem ser vistos enquanto constituintes de uma prática documentária que tem o intuito de "ver e dizer" o que se acredita que seja a criança enquanto objeto visível.

Sendo assim, à proporção que foram evidenciadas e problematizadas algumas constatações realizadas a partir das observações da docente, é possível dizer que, através da linguagem, nossas experiências culturais, sociais, emocionais, entre outras, podem ser nomeadas, fixadas, aprisionadas e definidas (mesmo que de modo instável e provisório) através de uma "gramática" que é introduzida, em grande parte, pelo discurso da Pedagogia e dos campos que a compõem. Nessa perspectiva, a prática de seleção é vista, portanto, como elemento integrante de uma rede de olhares que vigiam e colocam (em especial) as crianças e famílias sob permanente processo de observação e avaliação com vistas a identificar e corrigir as "irregularidades" percebidas. Dessa forma, prosseguindo a respeito do disciplinamento dos corpos, na próxima seção serão problematizadas as práticas do cotidiano.

\section{AS PRÁTICAS DO COTIDIANO}

Analisando o cotidiano da escola em que foi realizada a pesquisa, foi possível identificar e problematizar as práticas do cotidiano: descanso, alimentação e brincadeira "livre", devido ao fato de as mesmas evidenciarem a normatização das relações que as crianças, professoras, educadoras e funcionárias estabeleciam com o tempo, o espaço e "autoridades escolares". Através da discussão de tais práticas, foi possível perceber que o uso que é feito da normatização dos tempos e dos espaços está muitas vezes voltado para a padronização 
das condutas. Desse modo, será apresentado, a seguir, um panorama do funcionamento das referidas práticas no dia-a-dia da instituição escolar pesquisada.

O descanso, conhecido também como a "hora do sono", tem ocorrência diária na instituição. As crianças, ao chegarem à escola às $7 \mathrm{~h} 30 \mathrm{~min}$, "descansam" até às $8 \mathrm{~h}$, horário em que é servido o café da manhã. O almoço é servido às $11 \mathrm{~h} 45 \mathrm{~min}$. Após o término das refeições (de todas as turmas) e realização da escovação dos dentes, por volta das $12 \mathrm{~h} 30 \mathrm{~min}$, as crianças devem "descansar" até às $14 \mathrm{~h}$. Os grupos iniciais (2-3 anos) têm o período de "descanso" prolongado em $30 \mathrm{~min}$, e as crianças que fazem parte da turma do Pré B (as quais têm 6 anos de idade e freqüentam a escola somente no turno da tarde) não "descansam" ao chegarem à escola. É importante ressaltar que as crianças de tal grupo e professora, ao chegarem à escola às $13 \mathrm{~h}$, permanecem na praça até todos/as integrantes dos demais grupos despertarem, para "evitarem transtornos e falta de respeito em relação ao momento destinado ao descanso dos demais colegas" (Diário de Campo, 05/09/03). Tal prática baseia-se, entre outros aspectos, na "necessidade" institucional de vigilância constante, de controle rígido, extensivo e pormenorizado dos corpos, tempos/ espaços dos indivíduos. As crianças chegam à escola, tomam café da manhã, escovam os dentes e logo depois são orientadas a se deitarem nos colchonetes para "descansarem". Algumas crianças adormecem logo após deitarem, outras conversam, falam sozinhas, cantam, brincam com o corpo, levantam do lugar e pedem para ir ao banheiro, permanecendo durante todo o tempo acordadas. A resistência das crianças em relação a tal prática evidencia que o poder disciplinar não é exercido de forma unilateral, não é algo que se conquiste, que se possua, mas que todos os indivíduos (crianças, professoras e funcionárias) exercem/sofrem.

A alimentação das crianças na instituição inicia com o café da manhã, que é servido às 8 h. Após o café da manhã, por volta das $10 \mathrm{~h}$ é servido o lanche e, às $11 \mathrm{~h} 45 \mathrm{~min}$, o almoço. O lanche da tarde é servido às $15 \mathrm{~h}$ e a janta às $17 \mathrm{~h}$. Nas sextas-feiras, a janta começa a ser servida às 16 h30 min, para facilitar o funcionamento dos serviços de cozinha e limpeza (em relação ao tempo investido na limpeza dos pratos e talheres, assim como na limpeza do refeitório que as crianças utilizam durante as refeições). Durante o primeiro semestre, as crianças do M1 (2-3 anos de idade) realizam as refeições 
na sala de aula; no decorrer do segundo semestre, começam a realizar os primeiros contatos com o espaço do refeitório. Conforme relato de uma funcionária, tal medida é tomada "porque os pequenos não sabem comer sozinhos, sem a ajuda da professora, e por isso demoram muito tempo" (Diário de Campo, 18/07/03).

Desse modo, o caminho para o refeitório é diariamente percorrido diversas vezes pelas professoras e crianças da escola. A organização dos momentos de café da manhã, lanche, almoço e janta é muito importante, uma vez que, além de serem momentos de alimentação, constituem-se como elementos ordenadores do cotidiano escolar, que incidem no controle dos corpos, tempos/espaços dos indivíduos. Os horários de alimentação (muitas vezes inflexíveis) devem ser cumpridos de acordo com as deliberações institucionais. Para o cumprimento de tais horários, os/as "personagens" da casa vigiam-se uns aos outros. A equipe diretiva acompanha efetivamente se os horários de servir as refeições estão sendo cumpridos pelas funcionárias da cozinha. As funcionárias da cozinha, a partir de uma vigilância constante e detalhada, observam se as professoras estão cumprindo os horários de trazer as crianças para o refeitório. Por outro lado, as próprias professoras controlam o horário de permanência das crianças de suas turmas no refeitório, assim como o horário de suas colegas. É possível, a partir de tal situação, perceber que se constitui na escola uma pirâmide de olhares (FOUCAULT, 1987; 2003a), com o intuito de evitar que infrações sejam cometidas. Dessa forma, é possível realizar uma aproximação com as análises desenvolvidas por Barbosa (2000) em sua pesquisa, quando a autora ressalta que, nas instituições de educação infantil, todos os profissionais conhecem as rotinas e, com isso, controlam a vida uns dos outros.

A brincadeira "livre" não está prevista na rotina semanal. Tal momento ocorre, com freqüência, ao término das atividades (descritas na rotina semanal) que antecedem os períodos de alimentação, quando as crianças podem brincar "livremente" com seus pares. E o final das brincadeiras acontece com o chamado da professora para a realização das refeições. Em algumas ocasiões, o momento da brincadeira "livre" (que acontece no turno da tarde, antes da janta) ocorre no pátio da escola. É interessante observar que tal proposta ocorre dessa forma somente com os grupos de Pré A e B (5 -6 anos), pois os demais grupos, devido ao fato de realizarem um número menor de atividades dirigidas pelas professoras, têm mais tempo para 
brincar dentro e fora da sala de aula. A brincadeira "livre" não está prevista na rotina semanal das turmas e pode ser considerada como uma proposta de transição entre as atividades (ditas "oficiais"), que são desenvolvidas no cotidiano da escola.

O tempo (em torno de quinze minutos) disponível para as crianças brincarem, geralmente, é o que antecede os horários previstos para a sua alimentação. Ao término das atividades planejadas e orientadas pelas professoras, as crianças podem brincar com seus pares na sala de aula e, em algumas situações, nas áreas externas (pátio e praça), sempre acompanhadas da professora responsável pela turma. A utilização das áreas externas da escola pelas crianças torna-se muitas vezes motivo de disputa e conflito entre as docentes, já que o espaço físico de tais locais (por ser pequeno) restringe-se à utilização de uma turma de cada vez. A partir das considerações abordadas e das contribuições de Ratto (2004), é possível ressaltar que a prática escolar da brincadeira "livre", "materializa" relações sociais especificamente escolares, que geralmente se experimentam como "corretas" e "adequadas", passando a ser percebidas pelos indivíduos como espontâneas e naturalizadas. Sendo assim, o tempo cronológico escolar - que estabelece os horários das brincadeiras, que regulamenta o início e o final das propostas, etc. - e o espaço físico escolar - que estabelece os limites de dentro e fora (sala de aula/ pátio/praça), os deslocamentos das crianças, a disposição dos brinquedos, etc. - podem ser considerados como estratégias que incidem no disciplinamento dos corpos dos indivíduos.

Sendo assim, é possível perceber que as práticas do cotidiano inscrevem em cada corpo uma dada forma de se ver, de se narrar, de se expressar, de se relacionar consigo e com os outros, designando uma posição de sujeito, que é atribuída como própria. Trata-se, de certo modo, de aprender a ser criança-escolar, professora/educadora, funcionária da educação infantil, constituindo um "modo de ser" que se estende através de um disciplinamento contínuo, suscetível a resistências e (re)significações por parte dos sujeitos envolvidos. Assim, é possível dizer que principalmente as crianças (entre outros indivíduos) lidam com tais práticas e são inscritas por elas, ao mesmo tempo em que resistem e as ressignificam. Relacionados a essas práticas estão os rituais comemorativos, prática integrante do planejamento escolar que será apresentada na próxima seção. 


\section{OS RITUAIS COMEMORATIVOS}

O que são os rituais comemorativos? Como funcionam? Quais os seus efeitos? Tais questionamentos foram desencadeados pela informação prestada por uma professora de que "as inúmeras festas que acontecem na escola já se tornaram rituais comemorativos, pois se alteram apenas as temáticas e repetem-se sempre as mesmas ações" (Diário de Campo, 19/09/03). Ao participar de alguns desses rituais, foi possível observar que eles apresentam uma repetição de procedimentos de natureza pedagógica direcionados ao disciplinamento dos corpos infantis, em termos de atitudes, comportamentos e hábitos, tendo em vista uma eficiente aprendizagem.

Tais procedimentos podem ser assim descritos: organização das crianças por faixa etária no espaço em que se realizam as comemorações; utilização de quatro horas (divididas em dois turnos) para a realização das propostas; apresentações artísticas das crianças e/ ou professoras; definição e exploração de uma temática para a festa através da decoração do salão; proposição de competições entre as crianças; avaliação da comemoração através de registro fotográfico e relatório escrito (pelas professoras, educadoras e equipe diretiva); realização de merenda "especial"; reorganização dos horários da instituição e rotinas das salas de aula; presença da equipe diretiva e assessora da Secretaria Municipal de Educação e Pesquisa.

Com o objetivo de ensinar, através de certa disposição e ordenação do corpo daqueles que aprendem e das coisas que são aprendidas, os rituais (entre outras práticas escolares) possibilitam a ação do poder disciplinar. Através da ação do referido poder, pode-se dizer que o saber pedagógico se instaura e redefine o estatuto de criançaescolar na instituição educacional. As propostas desencadeadas nos rituais comemorativos (entre outras) desenvolvem-se através da ação do poder disciplinar e seus instrumentos, que possibilitam a produção de subjetividades dóceis. Essas propostas apresentam características que lhes são peculiares e se desenvolvem em sucessivas etapas de curta duração.

No primeiro momento, é realizada a abertura da festa através do pronunciamento da equipe diretiva e convidado/a, seguida de uma representante das profissionais que trabalham na instituição. Ao término da abertura, as crianças são posicionadas em espaços demarcados (em círculo no chão) por faixa etária e a merenda é 
servida pelas funcionárias. As competições entre os grupos iniciam após a alimentação. Algumas crianças representando suas turmas (com exceção do grupo de 2-3 anos) participam dos jogos propostos, visando à conquista de brindes para seus pares. O encerramento das comemorações é marcado pela liberação das crianças para brincarem no salão ao som de músicas infantis.

Nesse espaço social configurado pelas comemorações, o olhar pedagógico não cessa de objetivar os indivíduos, transformando-os em foco de observação. Assim, evidencia-se a urgência de a escola controlar, regular e normalizar a população infantil, através de táticas disciplinares que tomam os indivíduos, ao mesmo tempo, como objetos e instrumentos de seu exercício. Nesse sentido, ao discutir os mecanismos de observação, Corazza (2001) assegura que esses indivíduos são interessados, implicados na constituição de políticas de identidades e comprometidos em determinadas relações de podersaber.

Tais mecanismos sutis disciplinam através de sua ação, pois as crianças são provocadas a evitar condutas "erradas" e a terem atitudes de constante cuidado ante o que pode ser considerado como uma falta. A finalidade dessa operação pode ser a produção de uma série de condutas adequadas, nas quais se encontram formalismos inerentes a um "bom aluno", a um "aluno educado", "civilizado". É importante ressaltar que essas comemorações provocam expectativas nas profissionais que trabalham na instituição, pois elas são avaliadas pela equipe diretiva (e convidados) em relação ao comportamento das crianças e à realização das propostas previstas. Dessa forma, é preciso levar em consideração que o "jogo" praticado na escola não ocorre somente em relação aos saberes que são ensinados, mas também quanto à constituição dos modos de ser professora, atendente, educadora, membro da equipe diretiva, funcionária, etc. Tais pessoas, sejam elas adultos ou crianças, "aprendem" modos peculiares de serem integrantes e de se relacionarem no(s) espaço(s) da escola infantil.

Operacionaliza-se, assim, o dito por Foucault (1987; 2003a), de que as instituições de seqüestro (entre elas destaco as escolas infantis) podem ser consideradas como "máquinas" que disciplinam aqueles às quais são submetidas, imprimindo profunda e permanentemente certas disposições (disciplinares) que passam a operar pelo resto da vida. Esse conjunto de operações leva ao fim o poder disciplinar e tem como propósito a (normalização das condutas) transformação 
técnica dos indivíduos para adequá-los a uma norma. É importante ressaltar que a norma, conforme Skliar (2003), insiste em atrair para si todas as identidades e diferenças, tendo em vista ser o centro da gravidade, eixo a partir do qual se organizam, catalogam e classificam as coisas no mundo.

Nesse sentido, as contribuições dos autores possibilitam destacar que a disciplina não é regida pelo domínio da lei, que estabelece um conjunto de proibições, mas pelo da norma, que define uma codificação dos costumes. Pode-se dizer, portanto, que tal codificação se (re)significa nos rituais comemorativos, pois a instituição, através de um conjunto de técnicas de controle corporal, aponta o espaço, o tempo e os movimentos dos adultos/crianças, utilizando mecanismos econômicos que maximizam o corpo como força útil. Nesse espaço de relações, as pessoas são concebidas em uma série de estratégias reguladas de comunicação e práticas de poder que permitem a individualização e a subjetivação. Essas relações evidenciam a operação de micropoderes sobre os corpos, enquanto objetos a serem "manipulados" e "controlados", visando ao governo dos mesmos. Tendo realizado algumas análises no que diz respeito ao disciplinamento dos corpos nas práticas escolares da Educação Infantil, na próxima seção serão apresentadas as considerações finais desse trabalho.

\section{CONSIDERAÇÕES FINAIS}

A partir de todas as considerações apresentadas neste artigo a respeito das análises desenvolvidas na pesquisa - em que procurei problematizar a lógica disciplinar que movimenta algumas práticas escolares operacionalizadas na escola de educação infantil, evidenciando, sobretudo, alguns de seus efeitos - é possível dizer que tais análises foram realizadas a partir do referencial foucaultiano e da leitura dos registros das práticas escolares (produzidos em campo), nos quais se destacava o funcionamento dos operadores disciplinares. Nesse sentido, foi ressaltado nas análises que o que fazemos e somos não está previamente definido e que, por isso, é possível problematizarmos nossa constituição enquanto sujeitos.

É importante esclarecer que não houve pretensão de dizer "verdades", mas de somente deslocar o olhar, visibilizando práticas escolares que são próximas, imediatas e, de certo modo, tão ligadas 
às pessoas que atuam na Educação Infantil que, com freqüência, deixam de ser vistas, pois passam a ser incorporadas na rotina diária como algo "natural". Sendo assim, para finalizar este trabalho (sem, no entanto, encerrar a discussão) ouso dizer que, se assumirmos a perspectiva de que as práticas escolares são "produzidas", é possível desnaturalizá-las, repensá-las, reinventá-las, experimentando outras posições de sujeito, outros modos de agir e de pensar. Como nos ensina Schmid (2002, p. 321), "a arte de viver tem a ver com pessoas e situações concretas[...], mas não é possível pensar [e viver de outro modo], sem o cansativo trabalho de elaboração, sem a paciente elaboração de outras práticas". Desse modo, considero importante continuarmos atentos às práticas escolares na Educação Infantil, questionando a respeito de como elas funcionam e nos produzem enquanto sujeitos de uma determinada época. Talvez, seja o momento oportuno de nos perguntarmos a respeito do que estamos fazendo de nós mesmos, o que estamos fazendo com nossas crianças e de que modo estamos contribuindo para a produção de suas subjetividades na contemporaneidade.

\section{REFERÊNCIAS}

BARBOSA, M. C. S. Por amor $\mathcal{E}$ por força: rotinas na educação infantil. 2000, 275f. Tese (Doutorado em Educação) - Faculdade de Educação, Universidade Estadual de Campinas, Campinas, 2000.

CARY, N.; TREICHLER, P. A.; GROSSBERG, L. Estudos Culturais: uma introdução. In: SILVA, T. T. da. Alienígenas na sala de aula: uma introdução aos estudos culturais em educação. Petrópolis: Vozes, 2002. p. 7-38.

COSTA, M. V.; SILVEIRA, R. H.; SOMMER, L. H. Estudos culturais, educação e pedagogia. Revista Brasileira de Educação, Campinas, n. 23, p.36-61, maio/ago.2003.

CORAZZA, S. M. Olhos de poder sobre o currículo. In: . O que quer um currículo? : pesquisas pós-críticas em Educação. Petrópolis: Vozes, 2001. cap.2, p. 22-55.

FOUCAULT, M. Vigiar e punir. Tradução de Raquel Ramalhete. 25. ed. Petrópolis: Vozes, 1987. 288 p.

A verdade e as formas jurídicas. Tradução de Roberto Cabral de Melo Machado e Eduardo Jardim Morais. 3. ed. Rio de Janeiro: NAU, 
2003a.160 p.

. Poder e saber. In: . Ditos e escritos IV: estratégia poder - saber.

Rio de Janeiro: Forense Universitária, 2003b. p. 224-240.

GOELNER, S. V. A produção cultural do corpo. In: LOURO, G. L.; NECKEL, J. F. (Org.). Corpo, gênero e sexualidade: um debate contemporâneo na educação. Petrópolis: Vozes, 2003. p. 28-40.

HOUAISS, A. Dicionário Houaiss da língua portuguesa. 2. ed. Rio de Janeiro: Objetiva, 2004. 2922 p.

RATTO, A. L. S. Livros de ocorrência: disciplina, normalização e subjetivação. 2004, 322f. Tese (Doutorado em Educação) - Faculdade de Educação, Universidade Federal do Rio Grande do Sul, Porto Alegre, 2004.

SCHIMD, W. Em busca de um nuevo arte de vivir: la pregunta por el fundamento y la nueva fundamentación de la ética em Foucault. Valencia/ Espanha, 2002. 399p.

SILVA, T. T. As pedagogias psi e o governo do eu. In: . Liberdades reguladas: a pedagogia construtivista e outras formas de governo do eu. Petrópolis: Vozes, 1999. cap.1, p.7-13.

SKLIAR, C. Sobre a anormalidade e o anormal - notas para um julgamento (voraz) da normalidade. In: - Pedagogia (improvável) da diferença: e se o outro não estivesse aí? Rio de Janeiro: DPEA, 2OO3. cap. IV, p.151194.

VEIGA-NETO, A. Michel Foucault e os Estudos Culturais. In: COSTA, M. V. (Org.). Estudos Culturais em educação: mídia, arquitetura, brinquedo, biologia, literatura, cinema... Porto Alegre: UFRGS, 2000. p. 37-72.

WALKERDINE, V. Uma análise foucaultiana da pedagogia construtivista. In: SILVA, T. T. (Org.). Liberdades reguladas: a pedagogia construtivista e outras formas de governo do eu. Petrópolis: Vozes, 1999. p.143-216.

Encaminhado em: 08/03/07

Aceito em: 10/05/07 